\title{
sciendo
}

\author{
BULGARIAN ACADEMY OF SCIENCES
}

CYBERNETICS AND INFORMATION TECHNOLOGIES • Volume 21, No 2

Sofia $\bullet 2021 \quad$ Print ISSN: 1311-9702; Online ISSN: 1314-4081

DOI: $10.2478 /$ cait-2021-0023

\section{A Model for e-Learning Based on the Knowledge of Learners}

\author{
Ivaylo Blagoev, Gergana Vassileva, Vladimir Monov \\ Institute of Information and Communication Technologies, Bulgarian Academy of Sciences, 1113 Sofia, \\ Bulgaria \\ E-mails: ivaylo.blagoev@iict.bas.bgｇergana.vassileva@iict.bas.bg vladimir.monov@iict.bas.bg
}

Abstract: The presented work examines the existing approaches to providing e-Learning content based on learners' prior knowledge. An analysis of the existing tools for the development of e-Learning content is performed and their suitability for creating personalized learning content, reflecting the previous competencies of the learners, is carried out. In the paper we have used a step-by-step process of creating and providing personalized knowledge. For data analysis, an approach of describing small structural units of knowledge through competencies is used. As a result of our study we have proposed a conceptual model including interactive resources for analysis of the accumulated prior knowledge and tools for providing personalized content to the learners. Perspective directions for future work are also outlined.

Keywords: Personalized e-Learning, authoring tools, lifelong learning, e-Learning content development, prior knowledge analysis.

\section{Introduction}

E-Learning fully transforms the way knowledge is transferred and comprehended by the learners. Unlike the traditional method of teaching, e-Learning makes absorbing of the material easier and more effective. With the rapidly accelerating technological change, lifelong learning becomes a necessity. It can be addressed in the most adequate way by e-Learning.

Summarizing all reviewed definitions authors define e-Learning as using Internet to access learning materials, to interact with the content, teaching staff and other students, to get support and knowledge in study process and on the base of acquired knowledge learners to make their own opinion [1].

Providing processes in the field of modern e-Learning requires the participants in this process, including subject-matter experts, Instructional designers, e-Learning developers, trainers and administration and management of the training institution to have, in addition to competencies in the field of instructional design also a variety of skills in using the many different sophisticated tools to prepare a modern interactive online course.

Creating and delivering effective and engaging user learning content requires at least three main key tools. 
1. Authoring tools. To create a proper course for e-Learning, you need an authoring tool to facilitate this work. The definition of authoring tool is a program that helps you write hypertext or multimedia applications and allows you to create a final application by linking objects, such as a paragraph of text, an illustration, or a song. By defining the objects' relationships to each other, and by sequencing them in an appropriate order, authors (those who use authoring tools) can produce attractive and useful graphics applications [2].

2. Learning Management Systems (LMS). Throughout the distance learning process, LMS also known as the Virtual Learning Environments (VLE) or Learning Platforms have a significant role. The LMS could be defined as: "a software application or Web-based technology used to plan, implement, and assess a specific learning process" [3]. LMS are specialized training systems based on modern internet and web technologies [4]. On the other hand, it is believed that LMS arise due to the need to provide organizational, administrative and educational elements, as well as the inclusion of a variety of technological components [5].

Nowadays, personalised learning services are a key point in the field of online learning as there is no fixed learning path which is appropriate for all learners. However, traditional learning systems ignore these services requirements and deliver the same learning content to all learners. This approach may not be effective for learners with different backgrounds and abilities. In order to design an adaptive learning content, we need to enable the delivery of learning content according to particular learner's needs [6].

3. Data Analysis. As pointed out in [7] Data science allows for the combination of various approaches including techniques connected to data analysis in the field of statistics, machine learning, artificial intelligence, programming, communications, etc., in order to improve the teaching process by creating a virtual e-Learning space. Furthermore, a method for evaluation and prognosis of the knowledge, skills and competencies of the students in the virtual learning space in the area of new and emerging technologies is developed in [8].

The creation of personalized learning content is also important in educating the learners in some fundamental disciplines as science, technology, engineering and mathematics known as an interdisciplinary STEM-education. The effect of building an augmented reality to enhance the efficiency of the learning process in this area is studied in [9] and [10].

The main goal in building adaptive e-Learning based on students' prior knowledge is to build an optimized and faster personalized learning path for each learner, which in addition will reduce the time for knowledge accumulation and increase the motivation of the learner to complete the e-course.

The reversal of the learning process and the gradual encounter of the learner with different problems with different degrees of complexity before presenting the actual learning content, significantly increases the interest of the learners.

For the effective construction of adaptive e-Learning based on prior knowledge, it is necessary for the authors of online courses to have a tool for developing an interactive analytical complex that immerses the learner in a real environment in which he is required to apply the knowledge he already has. The analytical 
components, which are test questionnaires, cannot engage the learner and motivate $\mathrm{him} / \mathrm{her}$ to go through the analysis module.

The creation of personalized e-Learning content is a resource-intensive process that requires from the authors of such content a serious investment of time and knowledge of modern technologies in the field of e-Learning [11].

\section{Research methodology}

For the creation of a conceptual model for the development of personalized e-Learning content based on the prior knowledge of learners from a methodological point of view, we analuze the existing approaches and provide a description of the processes necessary to build personalized e-Learning content.

2.1. Approaches to providing e-Learning content based on learners' prior knowledge

An evolutionary approach for transition from computer based training to building a flexible and adaptable e-Learning environment is presented in [12]. The proposed infrastructure is particularly specialised for software engineering education. Further developments [13] lead to the creation of a service- and agent-oriented educational portal DeLC (Distributed e-Learning Centre). Although its context-oriented and adaptive architectures, certain shortcomings of DeLC have been overcome and a new infrastructure, known as Virtual Educational Space is developed incorporating the learning process and the real physical world [14].

In the context of our study, the e-Learning infrastructure can be considered adaptive if it provides user monitoring, database-specific modelling, analysis of user requirements and activity preferences, and is presented in an appropriate way in linked models. It is essential to analuze the accumulated knowledge available in the learners to support the learning process [15]. Numerous models have been developed to provide e-Learning content based on the evening accumulation of competence of each individual learner [16].

To create our model, we adopt a methodology based on the following four concepts.

Preliminary knowledge. To ensure an effective process of personalized learning, a detailed analysis of the knowledge accumulated in the learners, stored in an individual competence profile, is required. The already acquired knowledge of the learner has a strong impact on the future acquisition and understanding of the provided knowledge. Previous experience in a subject area for each learner can be analuzed through assessment components to prepare a detailed picture of the learner's level of knowledge.

User profiling. It is important to solve a problem with how to assess in detail the current knowledge of the learner, when details of this accumulated knowledge are distributed in different incompatible systems. When there is an opportunity to evaluate the previous experience of the learners, the obtained data are stored in a user profile. The user profile is a database of keywords that reflect the learner's knowledge. 
Adaptation rules. User profile of the students stores and updates data on the various activities and achieved results of the students in the system. The continuous learning process is monitored by the adaptive system and user models, as a result of which the individual user profiles are updated. The adaptation model must adapt the content and the learning path to meet the user requirements, based on the data accumulated for the learner, which are stored in the user profile.

Supporting learner diversity. The development of personalized e-Learning content provides learners with alternative learning activities to acquire key competences and improve the user experience. It is necessary that the training content must correspond to the different profile of the learners, cover the different learning styles and combine the maximum number of different media.

\subsection{Step-by-step process of creating and providing personalized knowledge}

The development of personalized learning content is a process in which the e-Learning course is built up of a module analyzing the prior knowledge of the learners and a module that provides the learning content with a unique scope for each learner, based on the results of the analyzing complex.

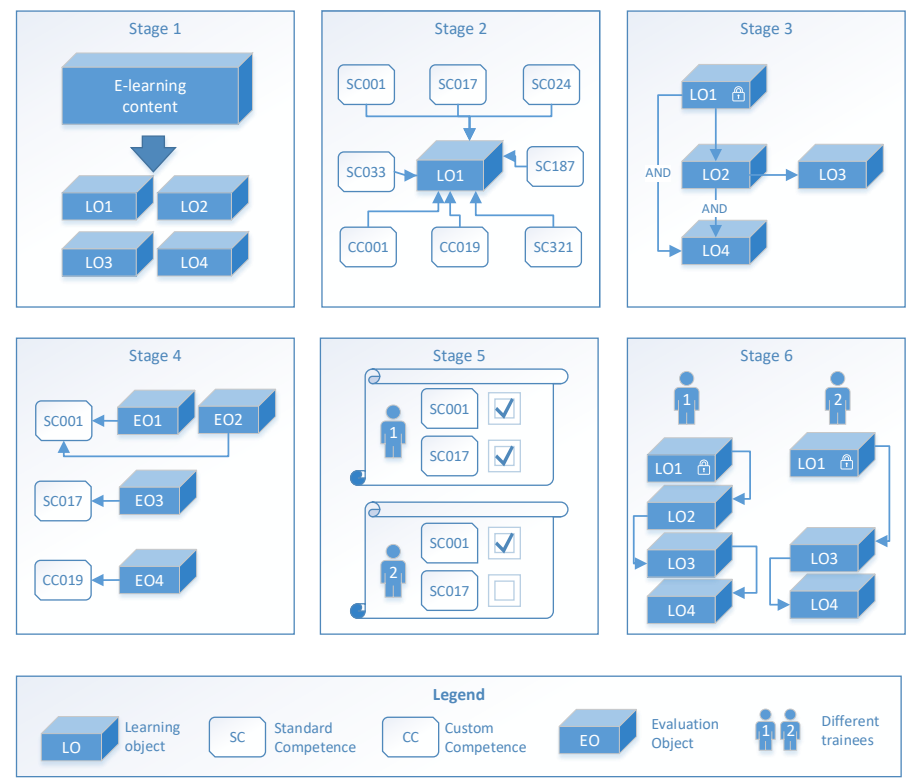

Fig. 1. Stages in developing and delivering personalised e-Learning

In order to realize this seemingly less complex process, a sequence of a number of actions for fragmentation and linking of the training content is needed, which include the following six stages [17].

- Stage 1. Learning objects are decomposed into small units of learning content.

- Stage 2. Learning objects are described with necessary competences.

- Stage 3. Each learning object is linked with other learning objects.

- Stage 4. Construction of evaluative/analyzing components. 
- Stage 5. Developing learner competence profile.

- Stage 6. The individual learners are provided with access to the learning content based on the competence profile.

The above stages are illustrated in Fig. 1 and described in the sequel.

\subsubsection{Decomposing and describing the learning content (Stage 1 and Stage 2)}

At this step, it is necessary to divide the whole content of the training into small units of knowledge, called Learning objects (LO) [18], which are subsequently described with labels. As it is a question of describing knowledge, it is most appropriate for these Learning objects in this case to be described with competencies. Competences, in turn, can be several different types with a range of knowledge, skills or abilities.

\subsubsection{Linking the learning objects (Stage 3)}

At this stage, the creators of personalized content determine the mandatory nature of the individual learning objects, as well as the relationship between them. On this basis and as a result after the construction and passing through the analytical complex the trainee is provided with an individual training path with optimized scope, but in accordance with the need to pass mandatory parts of the training.

\subsubsection{Construction of an analysis complex (Stage 4)}

The analysis complex is a combination of interactive slides, quizzes, questionnaires, learning labyrinth and even specific assignments to the learners with the possibility of authors' feedback. At this stage, it is important to determine the conditions under which each item is reported as completed. The general term "Completed" means that the learner has demonstrated sufficient knowledge or skills to be considered to have demonstrated the required level of knowledge in the area being analyzed. As a fundamental part of the work of the model here is also the individual assessment or analysis components to be described with competencies, so that on this basis as a result of going through the analysis component to generate the individual competence profile of the learner.

At this stage, it is essential that the tool used to create the elements of the analytics complex has enough functionality to create interactive content, such as interactive video labyrinths, flip cards, drag and drop activities and other elements that are most engaging. This ensures the necessary motivation to go through this process.

2.2.4. Developing Learner Competence Profile and personalized education (Stage 5 and Stage 6)

As a result of the passage of the individual components of the analyzing complex of the learner, a competence profile is formed - a kind of dossier with the demonstrated competencies. Based on the connection between the individual learning objects, realized as a result of the previous two stages, a personalized training path is created for each trainee.

The creation of a personal profile of the trainee allows after the completion of the training a comparative analysis of the competencies of the trainee before and after 
the e-Learning path to be made, thus aiming to analyze the quality and effectiveness of e-Learning.

In order to make the connection between the analyzing complex and the training content, it is necessary for the individual particles of knowledge to be described (parameterized) with labels/tags, which will realize the connection between the individual analytical components and the individual parts of the optimized training content. Creating a database of descriptive elements is a complex and slow process, and existing software solutions do not offer the use of ready-made databases with elements to describe knowledge.

\subsection{Analysis of the existing tools for the development of e-Learning content}

In the evaluation of the analyzing tools, an evaluation methodology based on criteria proposed in [19] is used, which are defined as essential to provide an opportunity to build personalized e-Learning content.

To assess the importance of the given functionality on the whole process of providing e-Learning content based on the prior knowledge of the learners, a 5-point scale presented in Table 1 is used.

Table 1. Comparative analysis of tools for e-Learning content development

\begin{tabular}{|c|l|}
\hline Degree & \multicolumn{1}{|c|}{ Degree of influence } \\
\hline $\mathbf{0}$ & $\begin{array}{l}\text { It does not in any way affect the achievement of interactivity or the creation of } \\
\text { personalized learning content }\end{array}$ \\
\hline $\mathbf{1}$ & $\begin{array}{l}\text { It is not essential for achieving interactivity or creating personalized learning } \\
\text { content }\end{array}$ \\
\hline $\mathbf{2}$ & $\begin{array}{l}\text { Slightly helps to achieve interactivity, but its absence would not prevent the } \\
\text { creation of personalized learning content }\end{array}$ \\
\hline $\mathbf{3}$ & $\begin{array}{l}\text { Strongly supports the process of interactivity and motivation of learners, but its } \\
\text { absence would not prevent the creation of personalized learning content }\end{array}$ \\
\hline $\mathbf{4}$ & $\begin{array}{l}\text { Functionality without which it is impossible to create personalized learning } \\
\text { content }\end{array}$ \\
\hline
\end{tabular}

To determine the extent to which a given tool meets the functional requirements for achieving personalized learning content and interactivity against the two groups of criteria defined in advance, a 6-point scale for conformity assessment is used, presented in Table 2 [19].

Table 2. Authoring tools compliance evaluation scale

\begin{tabular}{|c|l|}
\hline Degree & \multicolumn{1}{c|}{ Level of compliance } \\
\hline $\mathbf{0}$ & It does not meet the criterion at all \\
\hline $\mathbf{1}$ & It meets the requirements to a very small extent \\
\hline $\mathbf{2}$ & $\begin{array}{l}\text { Partly meets the given criterion, and the missing functionality cannot be } \\
\text { compensated }\end{array}$ \\
\hline $\mathbf{3}$ & $\begin{array}{l}\text { Partly meets the given criterion, and the missing functionality can be } \\
\text { compensated, through a combination of additional activities, which } \\
\text { slows down the construction }\end{array}$ \\
\hline $\mathbf{4}$ & $\begin{array}{l}\text { It meets almost completely the given criterion, and the missing } \\
\text { functionality is not essential }\end{array}$ \\
\hline $\mathbf{5}$ & It fully meets the given criterion \\
\hline
\end{tabular}


Table 3. Comparative analysis of tools for e-Learning content development

\begin{tabular}{|c|c|c|c|c|c|c|c|c|c|}
\hline \multirow[b]{2}{*}{ No } & \multirow[b]{2}{*}{ Criteria } & \multicolumn{2}{|c|}{ Assessed tool } & \multicolumn{2}{|c|}{$\begin{array}{c}\text { Articulate } \\
\text { storyline }\end{array}$} & \multicolumn{2}{|c|}{ Adobe captivate } & \multicolumn{2}{|c|}{ iSpring } \\
\hline & & \begin{tabular}{|c|}
$\begin{array}{c}\text { Degree } \\
\text { of } \\
\text { influence }\end{array}$ \\
\end{tabular} & $\begin{array}{l}\text { Weighting } \\
\text { factor }\end{array}$ & $\begin{array}{c}\text { Level } \\
\text { of } \\
\text { compliance }\end{array}$ & Result & \begin{tabular}{|c|}
$\begin{array}{c}\text { Level } \\
\text { of } \\
\text { compliance }\end{array}$ \\
\end{tabular} & Result & $\begin{array}{c}\text { Level } \\
\text { of } \\
\text { compliance }\end{array}$ & Result \\
\hline 1 & 2 & 3 & 4 & 5 & 6 & 7 & 8 & 9 & $\mathbf{1 0}$ \\
\hline 1 & $\begin{array}{l}\text { F1 General functionality for } \\
\text { creating interactive content }\end{array}$ & & 64.04 & & 51.91 & & 53.71 & & 54.61 \\
\hline 1.1 & $\begin{array}{l}\text { Learner-based interactivity } \\
\text { management }\end{array}$ & 4 & 4.49 & 5 & 4.49 & 5 & 4.49 & 5 & 4.49 \\
\hline 1.2 & Create an interactive video & 3 & 3.37 & 5 & 3.37 & 5 & 3.37 & 5 & 3.37 \\
\hline 1.3 & $\begin{array}{l}\text { Creating a learning path through } \\
\text { the content (setting completion } \\
\text { requirements and prerequisites for } \\
\text { access to individual parts of the } \\
\text { training) }\end{array}$ & 4 & 4.49 & 5 & 4.49 & 5 & 4.49 & 5 & 4.49 \\
\hline 1.4 & $\begin{array}{l}\text { Combining different types of } \\
\text { training content (audio, video, } \\
\text { text, photos on one page / slide) }\end{array}$ & 3 & 3.37 & 5 & 3.37 & 5 & 3.37 & 5 & 3.37 \\
\hline 1.5 & $\begin{array}{l}\text { Create effects to show, hide and } \\
\text { attract attention }\end{array}$ & 3 & 3.37 & 5 & 3.37 & 5 & 3.37 & 5 & 3.37 \\
\hline 1.6 & $\begin{array}{l}\text { Embed video from external } \\
\text { sources }\end{array}$ & 0 & 0.00 & 5 & 0.00 & 5 & 0.00 & 5 & 0.00 \\
\hline 1.7 & $\begin{array}{l}\text { Built-in library of shapes and } \\
\text { icons }\end{array}$ & 0 & 0.00 & 3 & 0.00 & 4 & 0.00 & 4 & 0.00 \\
\hline 1.8 & $\begin{array}{l}\text { Management of the structure of } \\
\text { modules, topics and slides }\end{array}$ & 5 & 5.62 & 4 & 4.49 & 5 & 5.62 & 5 & 5.62 \\
\hline 1.9 & $\begin{array}{l}\text { Automatic generation of course } \\
\text { index }\end{array}$ & 1 & 1.12 & 4 & 0.90 & 5 & 1.12 & 5 & 1.12 \\
\hline 1.10 & Video editor & 2 & 2.25 & 5 & 2.25 & 5 & 2.25 & 5 & 2.25 \\
\hline 1.11 & Image editor & 2 & 2.25 & 5 & 2.25 & 5 & 2.25 & 5 & 2.25 \\
\hline 1.12 & $\begin{array}{l}\text { Creating learning objects to be } \\
\text { used for multiple courses }\end{array}$ & 1 & 1.12 & 1 & 0.22 & 2 & 0.45 & 1 & 0.22 \\
\hline 1.13 & $\begin{array}{l}\text { Tools for communication between } \\
\text { creators of educational content }\end{array}$ & 1 & 1.12 & 5 & 1.12 & 0 & 0.00 & 0 & 0.00 \\
\hline 1.14 & Version control & 1 & 1.12 & 0 & 0.00 & 0 & 0.00 & 0 & 0.00 \\
\hline 1.15 & $\begin{array}{l}\text { Ability to create your own } \\
\text { templates }\end{array}$ & 1 & 1.12 & 3 & 0.67 & 2 & 0.45 & 1 & 0.22 \\
\hline 1.16 & $\begin{array}{l}\text { Centralized management of } \\
\text { course design settings }\end{array}$ & 1 & 1.12 & 3 & 0.67 & 3 & 0.67 & 3 & 0.67 \\
\hline 1.17 & Test management module & 4 & 4.49 & 5 & 4.49 & 5 & 4.49 & 5 & 4.49 \\
\hline 1.18 & $\begin{array}{l}\text { Standard types of questions } \\
\text { (multiple choice, true-false) }\end{array}$ & 4 & 4.49 & 5 & 4.49 & 5 & 4.49 & 5 & 4.49 \\
\hline 1.19 & $\begin{array}{l}\text { Create questions for working with } \\
\text { text (filling in words, dragging } \\
\text { words, choosing words, pointing } \\
\text { words and pointing letters) }\end{array}$ & 3 & 3.37 & 0 & 0.00 & 0 & 0.00 & 0 & 0.00 \\
\hline 1.20 & $\begin{array}{l}\text { Interactive types of questions } \\
\text { (drag and drop, flip cards, } \\
\text { ordering, hotspots, etc.) }\end{array}$ & 3 & 3.37 & 5 & 3.37 & 5 & 3.37 & 5 & 3.37 \\
\hline 1.21 & $\begin{array}{l}\text { Add an image, audio or video to } \\
\text { the text of the question }\end{array}$ & 3 & 3.37 & 4 & 2.70 & 5 & 3.37 & 5 & 3.37 \\
\hline 1.22 & $\begin{array}{l}\text { Create automated unique tests } \\
\text { with automatic calling of } \\
\text { questions by categories } \\
\end{array}$ & 4 & 4.49 & 5 & 4.49 & 5 & 4.49 & 5 & 4.49 \\
\hline 1.23 & Question Bank & 1 & 1.12 & 5 & 1.12 & 5 & 1.12 & 5 & 1.12 \\
\hline 1.24 & $\begin{array}{l}\text { Configuration of the assessment } \\
\text { (weight for each component, } \\
\text { inclusion of a requirement for } \\
\text { passing separate parts of the } \\
\text { training, minimum final } \\
\text { assessment, determination of } \\
\text { mandatory components) }\end{array}$ & 4 & 4.49 & 3 & 2.70 & 4 & 3.60 & 4 & 3.60 \\
\hline 1.25 & Creating adaptive learning content & 3 & 3.37 & 2 & 1.35 & 2 & 1.35 & 4 & 2.70 \\
\hline
\end{tabular}


Table 3 (c on t in u e d)

\begin{tabular}{|c|c|c|c|c|c|c|c|c|c|}
\hline \multirow[b]{2}{*}{ No } & \multirow[b]{2}{*}{ Criteria } & \multicolumn{2}{|c|}{ Assessed tool } & \multicolumn{2}{|c|}{$\begin{array}{c}\text { Articulate } \\
\text { storyline }\end{array}$} & \multicolumn{2}{|c|}{ Adobe captivate } & \multicolumn{2}{|c|}{ iSpring } \\
\hline & & $\begin{array}{c}\text { Degree } \\
\text { of } \\
\text { influence }\end{array}$ & $\begin{array}{c}\text { Weighting } \\
\text { factor }\end{array}$ & \begin{tabular}{|c|}
$\begin{array}{c}\text { Level } \\
\text { of } \\
\text { compliance }\end{array}$ \\
\end{tabular} & Result & $\begin{array}{c}\text { Level } \\
\text { of } \\
\text { compliance }\end{array}$ & Result & $\begin{array}{c}\text { Level } \\
\text { of } \\
\text { compliance }\end{array}$ & Result \\
\hline 1 & 2 & \begin{tabular}{|l|}
3 \\
\end{tabular} & 4 & 5 & 6 & 7 & 8 & 9 & 10 \\
\hline 2 & $\begin{array}{l}\text { F2 Specific functional } \\
\text { requirements to provide } \\
\text { personalized learning content }\end{array}$ & & 31.46 & & 6.52 & & 6.52 & & 6.52 \\
\hline 2.1 & $\begin{array}{l}\text { Possibility to create an analytical } \\
\text { block before accessing the } \\
\text { training itself }\end{array}$ & 4 & 4.49 & 3 & 2.70 & 3 & 2.70 & 3 & 2.70 \\
\hline 2.2 & $\begin{array}{l}\text { Describing the learning objects } \\
\text { with tags }\end{array}$ & 4 & 4.49 & 1 & 0.90 & 1 & 0.90 & 1 & 0.90 \\
\hline 2.3 & $\begin{array}{l}\text { Describe evaluation components } \\
\text { with tags }\end{array}$ & 4 & 4.49 & 1 & 0.90 & 1 & 0.90 & 1 & 0.90 \\
\hline 2.4 & $\begin{array}{l}\text { Use a built-in library of } \\
\text { competencies as an alternative to } \\
\text { tags }\end{array}$ & 2 & 2.25 & 0 & 0.00 & 0 & 0.00 & 0 & 0.00 \\
\hline 2.5 & $\begin{array}{l}\text { Ability to create mazes by } \\
\text { defining the correct/incorrect } \\
\text { output }\end{array}$ & 3 & 3.37 & 3 & 2.02 & 3 & 2.02 & 3 & 2.02 \\
\hline 2.6 & $\begin{array}{l}\text { Management of the achieved } \\
\text { result for skipping a slide during } \\
\text { the preparation of the individual } \\
\text { training package }\end{array}$ & 4 & 4.49 & 0 & 0.00 & 0 & 0.00 & 0 & 0.00 \\
\hline 2.7 & $\begin{array}{l}\text { Define required slides regardless } \\
\text { of the result }\end{array}$ & 4 & 4.49 & 0 & 0.00 & 0 & 0.00 & 0 & 0.00 \\
\hline 2.8 & $\begin{array}{l}\text { Opportunity for the learner to } \\
\text { review the missed content }\end{array}$ & 1 & 1.12 & 0 & 0.00 & 0 & 0.00 & 0 & 0.00 \\
\hline 2.9 & $\begin{array}{l}\text { Analysis of missed content with } \\
\text { low score after final evaluation }\end{array}$ & 1 & 1.12 & 0 & 0.00 & 0 & 0.00 & 0 & 0.00 \\
\hline 2.10 & $\begin{array}{l}\text { Ability to transfer data on } \\
\text { accumulated competencies to the } \\
\text { LMS }\end{array}$ & 1 & 1.12 & 0 & 0.00 & 0 & 0.00 & 0 & 0.00 \\
\hline \multicolumn{4}{|c|}{ Assessed tool and overall result } & $\begin{array}{c}\text { Articulate } \\
\text { storyline }\end{array}$ & 58.43 & \begin{tabular}{|c|} 
Adobe \\
captivate
\end{tabular} & 60.22 & iSpring & 61.12 \\
\hline
\end{tabular}

For the purposes of the analysis, two key groups of criteria have been developed, which have the greatest influence on determining the degree of suitability of the tools for developing online courses for creating personalized and at the same time interactive content.

The first group (F1 General functionality for creating interactive content) are basic functionalities for building interactive learning content, which is developed according to the decisions made by the user. The second group (F2 Specific functional requirements to provide personalized learning content), on the other hand, has the functional requirements needed to build the relationship between the interactive content for analysis and the actual learning content. The main goal of this group of requirements is to assess the suitability of the tools for analysis of the prior knowledge of the user, preparation of a competency profile and on this basis to provide a personalized and optimized training package.

In order to perform our analysis of the existing tools for development of eLearning content, we have selected three most popular and widely used tools: Articulate Storyline, Adobe Captivate and iSpring. At present, the authors do not have information on a specialized tool available, designed entirely to create personalized learning content based on the learner's prior knowledge which to be subjected to comparative analysis, along with leading commercial solutions. The results of our analysis are presented in Table 3. 
Using the degree of influence described in Table 1, we first determine to what extent each of the functionalities listed in column 2 of Table 3 is important for the construction of personalized training (column 3). Based on the degree of influence, the weight of each of the components and the group of components is determined in column 4. Using the scale of conformity assessment from Table 2 , we determine to what extent the given functionality is represented in the specific software solution (columns 5, 7 and 9). In columns 6, 8 and 10 of Table 3 on the basis of the methodology for evaluation of e-Learning systems developed in [19], we obtain a weighted result reflecting the degree of influence of each functionality for the development of personalized learning.

As a result of the analysis, it is evident that the analized software solutions, although leading and popular in the industry, achieve low results when considered in the context of creating personalized learning based on the prior requirements of the learners. The specific results of all three software tools are about 60 points with a maximum score of 100 points, which is practically unsatisfactory. One possible reason for this result is that existing tools for the development of e-Learning content on the market focus on interactivity, effects and the inclusion of various multimedia elements. Thus, they are lacking the necessary functionality that allows for automatic linking of resources used to assess competencies and on this basis, to build individual learning path for each learner.

\section{Main result}

In this section we present the developed model for creating of personalized e-Learning content including its basic components and tools.

Building an adaptive online course in most cases requires the use of open assessment components, i.e., components that require the intervention of trainers. In this case, it is extremely important to have a full integration between the tool for building adaptive learning content and the system through which it is provided to learners. At present, there are no widely used integrated and complex solutions that unite the whole process of creating, describing, linking and providing adaptive online courses, which is the main motivation of performing this research work.

\subsection{Model description}

The model is designed to put into practice the Step-by-step process of creating and providing personalized knowledge. Through the development of mockup screens, a conceptual model and a visual prototype of a tool for creating personalized learning content has been created, through which the six stages reviewed in detail in Section 2.2 can be realized.

The basic tools of the model are illustrated by screens that mainly serve to create analyzing components necessary to build a competency profile and configure the relationship between the three main stages, which the learner will subsequently go through - analysis of prior knowledge, transition through optimized learning content 
based on of the demonstrated competencies and possible optional stage of final assessment.

\subsubsection{Authoring tool main screen}

The main screen of the training package illustrated in Fig. 2 provides access to the necessary tools for creating interactive content and provides access to all the accompanying menus for setting up and building custom training content.

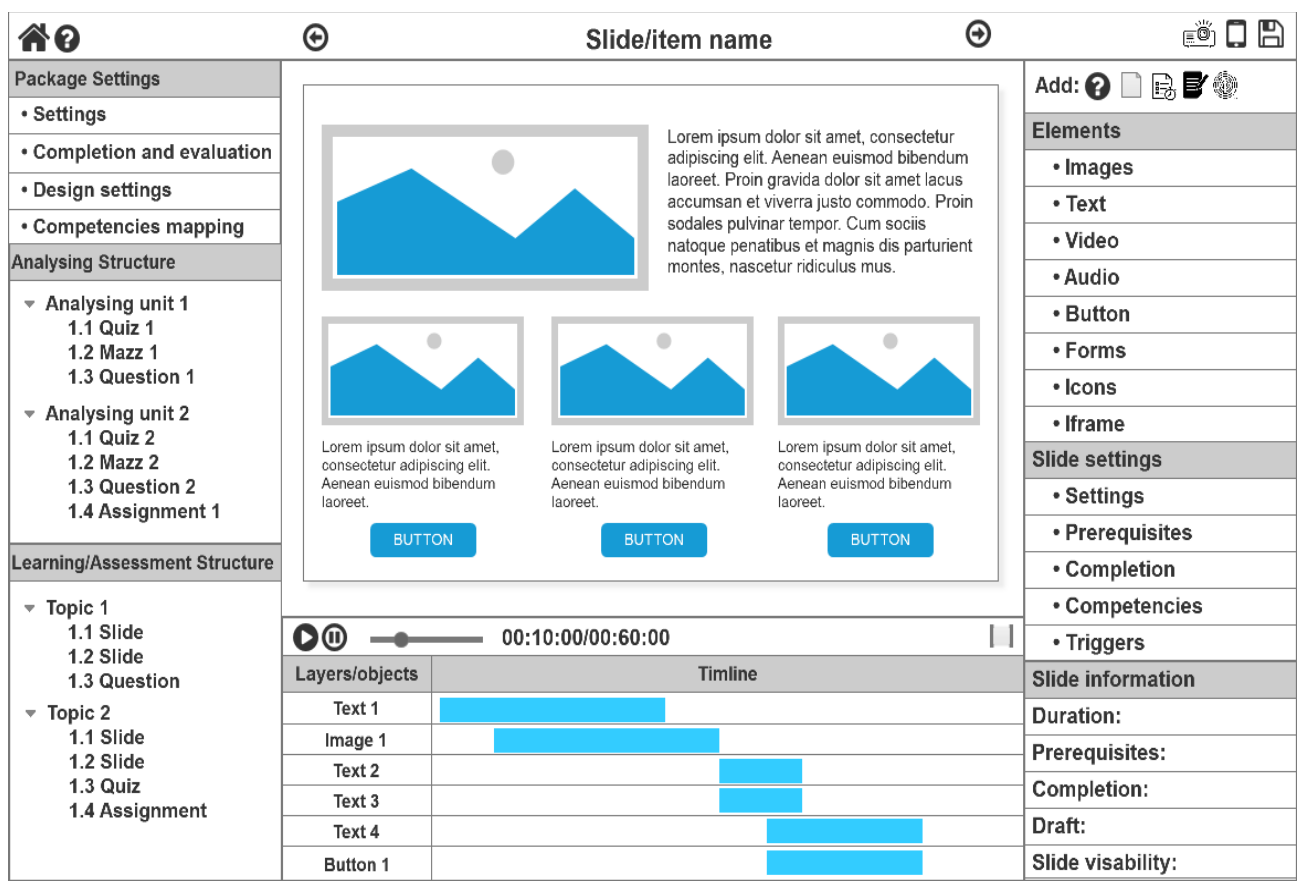

Fig. 2. AT main screen

The main components of this screen are the following:

- Stage - visual canvas in which the elements of each slide are located and configured.

- Timeline - presentation of the individual elements of the stage and their distribution over time with options for creating effects of showing, hiding and creating animations.

- Package Settings - the most important menu of the tool, where you set both key parameters, such as template selection, adaptability, multilingualism, design settings, as well as specific for building customization completion and evaluation, competencies mapping, discussed in detail below in the article.

- Analyzing Structure - structure of the content of the analyzing part of the training package. It can be opened in a separate screen and where it contains detailed information of the described competencies for the individual components, as well as the necessary result for validation of the competence. 
- Learning/Assessment Structure - structure of the actual content (delivery of personalized content and assessment components) of the training package. It can be opened in a separate screen and where it contains detailed information on the described competencies, the preliminary requirements and the completeness of each component, as well as the mandatory content.

- Quick add menu - menu to add: Questions, tests, training slides, mazes and assignments.

- Menu for selection of elements to add to the stage - a list of elements and their variations that the author can select and place on the stage.

- Slide Settings - key menu for slide management, where the slide competencies and the prerequisites and the way of slide completion are set, as by setting triggers it is configured which actions of the learner in which direction to take the training content.

- Slide Information - a block with summary information about the slide parameters.

\subsubsection{Adding competence to a slide or assessment component}

To facilitate the content authors and e-Learning developers it is necessary for the teams to have an integrated database of competencies, and at the European level the most appropriate is ESCO (European Skills, Competences, Qualifications and Occupations) - European multilingual classification of Skills, Competences, Qualifications and Occupations [20], which integrates more than 13,000 competencies for almost 3,000 occupations in 27 languages.

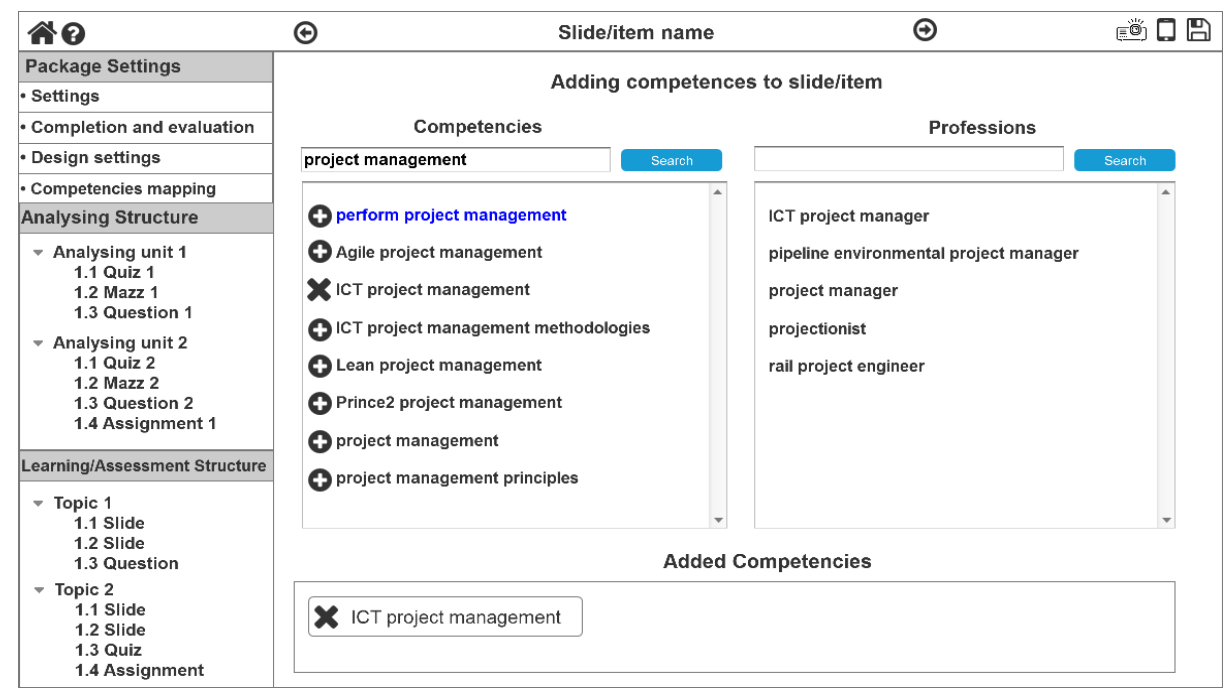

Fig. 3. Add competence to a slide

By describing learning objects with competencies a connection is built between an analytical complex and training content and this base creates an opportunity for personalization. 
The addition of competencies can be used both for training content and for elements of the analyzing complex or the final assessment. Fig. 3 illustrates the process of adding competencies as for the convenience of the authors a search is provided both by competence and by profession. The described link between competencies in the ESCO database makes it possible to click on a competency in the right list to load all professions for which it is applicable. Conversely, when clicking on occupations, the system displays a complete list of competencies that are entered in the database that are necessary for the particular profession.

Once the author of the training reaches the desired competence, he can use it and add it to the training unit, analyzing component or assessment component. In the absence of appropriate competence from the ESCO Database, the user can add his competence.

3.1.3. Determination of the percentage required for each tested competence and marking option as mandatory regardless of the result

\begin{tabular}{|c|c|c|c|c|c|}
\hline N?? & & & & & 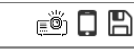 \\
\hline Package Settings & \multicolumn{5}{|c|}{ Determination of the percentage required for each tested competence } \\
\hline \begin{tabular}{|l} 
- Settings \\
- Completion and evaluation \\
\end{tabular} & \multirow{2}{*}{$\begin{array}{l}\text { Competencies } \\
\text { Competence } 1\end{array}$} & Percentage to pass & \multirow{2}{*}{$\begin{array}{c}\text { Slide } \\
\text { Slide } 1\end{array}$} & \multirow{2}{*}{ Required slide } & \multirow{2}{*}{$\begin{array}{c}\begin{array}{c}\text { Visible on } \\
\text { Request }\end{array} \\
\square\end{array}$} \\
\hline - Design settings & & $90 \%$ & & & \\
\hline - Competencies mapping & Competence 2 & $80 \%$ & Slide 2 & 0 & घ \\
\hline Analysing Structure & \multirow{2}{*}{ Competence 3} & \multirow{2}{*}{$95 \%$} & Slide 3 & 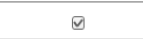 & 0 \\
\hline \multirow{3}{*}{\begin{tabular}{|l} 
Analysing unit 1 \\
$\mathbf{1 . 1}$ Quiz 1 \\
1.2 Mazz 1 \\
1.3 Question 1
\end{tabular}} & & & Slide 4 & 0 & 0 \\
\hline & Competence 4 & $92 \%$ & Slide 5 & 0 & 0 \\
\hline & Competence 3 & $75 \%$ & Slide 6 & 0 & 0 \\
\hline Learning/Assessment Structure & Competence 5 & $80 \%$ & Slide 7 & 0 & 0 \\
\hline \begin{tabular}{|l|} 
Topic 1 \\
1.1 Slide \\
1.2 Slide \\
1.3 Question \\
\end{tabular} & & & & & SAVE \\
\hline
\end{tabular}

Fig. 4. Determination of the percentage required for each tested competence

Through the functionality provided in Figure 4, the author of the training determines the required percentage collected by the analysts as the arithmetic mean of all analytical elements determined as assessing this competence. The author can choose to mark a slide as mandatory and show it to the user regardless of the achieved result. With the last option, the author can choose a slide to be visible to the learner, as it will not be shown to the learner when passing directly and will not be part of the personalized learning path, but can be accessed by the learner on request.

3.1.4. Screen for pursuit of gaps in the relationship of competencies between analytical complex, training content and final assessment components

The main purpose of this screen is to enable the author on one screen to track whether there are slides of content for which no analytical components or final assessment components have been introduced, as well as whether there is no training content for a particular competence. 


\begin{tabular}{|c|c|c|c|c|}
\hline \multicolumn{4}{|l|}{ N? } & 䢻口回 \\
\hline Package Settings & \multirow{2}{*}{\multicolumn{4}{|c|}{ Competence mapping monitoring }} \\
\hline - Settings & & & & \\
\hline - Completion and evaluation & $\begin{array}{l}\text { Analytical } \\
\text { component }\end{array}$ & Competencies & Slide & Required slide \\
\hline - Design settings & Quiz 1 & Competence 1 & Slide 1 & Quiz 3 \\
\hline - Competencies mapping & Question 1 & Competence 2 & & Assignment 2 \\
\hline Analysing Structure & & & Slide 3 & \\
\hline \multirow{3}{*}{$\begin{array}{l}\text { Analysing unit } 1 \\
1.1 \text { Quiz } 1 \\
1.2 \text { Mazz } 1 \\
1.3 \text { Question } 1\end{array}$} & Quiz 2 & Competence 3 & Slide 4 & Quiz 4 \\
\hline & Labyrinth & Competence 4 & & Question 2 \\
\hline & Assignment 1 & Competence 3 & Slide 6 & \\
\hline Learning/Assessment Structure & & Competence 5 & Slide 7 & Quiz 5 \\
\hline \multicolumn{5}{|l|}{\begin{tabular}{|l|} 
Topic 1 \\
1.1 Slide \\
1.2 Slide \\
1.3 Question
\end{tabular}} \\
\hline
\end{tabular}

Fig. 5. Competence mapping monitoring

3.1.5. Screen with the result of passing through the analyzing complex

The screen illustrated in Fig. 6 shows the user's result before moving on to the actual training content. This is a system screen that is not visualized by the author, because in practice the transition through the training package takes place in the LMS and cannot be accumulated in the authoring tool, but it shows what is the competence profile, based on which the learner receives personalized training package.

\begin{tabular}{|c|c|c|c|c|c|}
\hline \multicolumn{5}{|l|}{ 全? } & 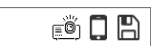 \\
\hline Package Settings & \multirow{2}{*}{\multicolumn{5}{|c|}{ Result of passing through the analyzing complex }} \\
\hline - Settings & & & & & \\
\hline - Completion and evaluation & Competencies & Percenta & pass & User score & Passed \\
\hline - Design settings & Competence 1 & $90 \%$ & $\nabla$ & $95.80 \%$ & घ \\
\hline - Competencies mapping & Competence 2 & $80 \%$ & 7 & $70.00 \%$ & 0 \\
\hline Analysing Structure & Competence 3 & $95 \%$ & 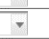 & $85.00 \%$ & 0 \\
\hline \multirow{3}{*}{$\begin{array}{l}\text { Analysing unit } 1 \\
1.1 \text { Quiz } 1 \\
1.2 \text { Mazz } 1 \\
1.3 \text { Question } 1\end{array}$} & Competence 4 & $\overline{92 \%}$ & $\nabla$ & $95.00 \%$ & ष \\
\hline & Competence 3 & $\overline{75 \%}$ & 7 & $25.00 \%$ & 0 \\
\hline & Competence 5 & $\overline{80 \%}$ & - & $45.00 \%$ & 0 \\
\hline \multicolumn{6}{|l|}{ Learning/Assessment Structure } \\
\hline $\begin{array}{l}\text { Topic } 1 \\
1.1 \text { Slide } \\
1.2 \text { Slide } \\
1.3 \text { Question }\end{array}$ & & & & & \\
\hline
\end{tabular}

Fig. 6. Result of passing through the analyzing complex

\subsection{Transfer data from the authoring tool to LMS}

Creating a single learner competency profile, both to aggregate data from multiple trainings and to track other activities, requires the content development tool and the LMS to be deeply integrated with each other. Alternatively, a standard for sharing data from training content can be used. To create "dynamic" learning pathways in line with previous actions and the overall progress of learners, the xAPI (Experience API) specification has been developed [21], through which learners' actions can be retrieved, recorded and processed in a distributed environment using of various educational materials, performing educational and/or other activities - games, 
simulations, etc. The aim is to support the adaptability of the learning content and to build profiles of the learners, regardless of the platform used. The specification xAPI is funded and supported by Advanced Distributed Learning (ADL) [21].

Based on these standards, it is possible to build a competence profile of the learner, which in addition to transmitting data from the analysing complex to the actual training package, can serve to create an external competency profile in the LMS, which will be collective of other digital and even physical activities of the learners.

\section{Conclusion}

An analysis of the existing tools for the development of e-Learning content has been performed and their suitability for creating personalized learning content, reflecting the previous competencies of the learners, is assessed. As a result of our study, a conceptual model including tools for creating interactive resources and evaluation of the accumulated prior knowledge by the learners is proposed. The model is designed for creating and delivering of personalised e-Learning on the basis of integrating an analytical complex including assessment tools, a data base of required competences, the training content, and the prior knowledge and skills of the learners. In this way the learner is given an effective way to go through the entire learning process and to acquire the desired competence profile. Future work will be concentrated on incorporating the proposed model in an interactive software system capable of building and providing e-Learning content according to the specific needs and prior knowledge of learners. In this direction an important area which outlines new opportunities and challenges for future research work is the development of appropriate e-Learning environment for disabled learners [22].

Finally, it should be noted that the transition to personalized learning based on learners' prior knowledge is a process that will definitely be the future of e-Learning. Currently, due to complex technological and non-technological factors, this process is complex and inefficient. With the development of efficient solutions in this area, supported by advanced technologies such as Artificial Intelligence (AI) and big data analysis, new achievements will gradually eliminate technological challenges and as a function of them will reduce costs and increase the motivation of both creators of personalized learning content and the learners themselves.

\section{References}

1. S e d l e n i e c e, M., S. C a ku 1 a. The Model of e-Learning Methods Development. - In: Annual Proceedings of Vidzeme University of Applied Sciences: "ICTE in Regional Development". 2008, pp. 73-82.

2. Ke y n e j a d, H., M. K h a d e m i, M. H a g h s h e $\mathrm{n}$ a s, H. K a b i r. e-Learning Content Authoring Tools and Introducing a Standard Content Constructor Engine. - In: Proc. of 2nd International Symposium on Computing in Science \& Engineering, Kusadasi, Turkey, 1-4 June, 2011.

3. A 1 i a s, A. N., A. M. Z a in u d d i n. Innovation for Better Teaching and Learning: Adopting the Learning Management System. - Malaysian Online Journal of Instructional Technology, Vol. 2, 2005, No 2, pp. 27-40. 
4. Avgeriou, P., A. Papas alouros, S. Retalis, M. Skordalakis. Towards a Pattern Language for Learning Management Systems. - Educational Technology \& Society, Vol. 6, 2003, No 2, pp. 11-24.

5. M o o r e, M. G., G. K e a r s 1 e y. Distance Education: A Systems View. Belmont, CA, Wadsworth Publishing Company, 1996.

6. Yarandi, M., H. Jahankhani, A-R. H. Tawil. A Personalized Adaptive e-Learning Approach Based on Semantic Web Technology. - Webology, Vol. 10, 2013, No 2, pp. 1-14.

7. Popchev, I. P., D. A. Or o z o va . Towards Big Data Analytics in the e-Learning Space. - Cybernetics and Information Technologies, Vol. 19, 2019, No 3, pp. 16-24.

8. P o p c h e v, I. P., D. A. O r o z o v a. Towards a Multistep Method for Assessment in e-Learning of Emerging Technologies. - Cybernetics and Information Technologies, Vol. 20, 2020, No 3, pp. 116-129.

9. Petrov, P. D., T. V. A t a n a s ov a. The Effect of Augmented Reality on Students' Learning Performance in Stem Education. - Information (Switzerland), Vol. 11, 2020, pp. 209-220.

10. Petro v, P. D., T. V. A t a n a s o va. Developing Spatal Mathematical Skills through Augmented Reality and Geogebra. - In: Proc. of 13th Annual International Conference of Education, Research and Innovation (ICERI'20), Spain, 2020, pp. 5719-5723.

11. B l a g o e v, I., V. Monov, G. V a s sile va. Main Problems in the Development and Provision of Personalized Electronic Training Content. - Ytelecomm, Vol. 6, 2019, pp. 55-61.

12. S t o y a n o v, S., I. P o p che v. Evolutionary Development of an Infrastructure Supporting the Transition from CBT to e-Learning. - Cybernetics and Information Technologies, Vol. 6, 2006, No 2, pp. 101-114.

13. S t o y a n ov, S., I. Pop che v, E. Doy che v, D. Mitev, V. Valk a nov, A. S to y a novaDo y cheva, V. Valk an ova, I. Minov. DeLC Educational Portal. - Cybernetics and Information Technologies, Vol. 10, 2010, No 3, pp. 49-69.

14. Glushkova, T., S. Stoyanov, I. Popchev, S. Cheresharov. Ambient-Oriented Modelling in a Virtual Educational Space. - Compt. Rend. Acad. bulg. Sci., Tome 71, 2018, No 3, pp. 398-406.

15. P a r a m y th i s, A., S. L o id l-R e i s in ge r. Adaptive Learning Environments and e-Learning Standards. - Electronic Journal on e-Learning, Vol. 2, 2004, No 1, pp. 181-194.

16. O'D on ne 11, E., S. L a w le s s, M. S h a r p, V. W a d e. A Review of Personalised e-Learning: Towards Supporting Learner Diversity. - International Journal of Distance Education Technologies, 2015, pp. 22-47.

17. V a s s i l e v a, G., V. M o n o v, I. B l a g o e v. e-Learning Model for Personalised Online Education Based on Data Analysis and Competence Profile. - In: Proc. of 11th International Conference on Education and New Learning Technologies, Palma, Spain. 1-3 July 2019, pp. 3726-3732.

18. P o $1 \mathrm{~s}$ a n i, P. R. Use and Abuse of Reusable Learning Objects. - Journal of Digital Information, Texas Digital Library, Vol. 3, 2003, No 4. 10 p.

19. B lagoev, I., V. Monov. Criteria and Methodology for the Evaluation of e-Learning Management Systems Based on the Specific Needs of the Organization. - International Journal of Education and Information Technologies, Vol. 12, 2018, pp. 134-141.

20. E S C O (European Skills, Competences, Qualifications and Occupations). Accessed 20 April 2019. https://ec.europa.eu/esco/portal/home

21. Rustici Software, xAPI Overview. Last visited on 03.04.2021. https://xapi.com/overview/

22. G 1 u s h k o v a, T., S. S t o y a n o v, I. P o p c h e v. Internet of Things Platform Supporting Mobility of Disabled Learners. - International Journal of Bio-Automation, Vol. 23, 2019, No 3, pp. 355-368.

Received: 16.02.2021; Second Version: 18.03.2021; Third Version: 23 .04.2021; Accepted: 14.05.2021 